\title{
Can Alcohol Intake from Mouthwash be Measured in Epidemiological Studies? Development and Validation of Mouthwash Use Questionnaire with Particular Attention to Measuring Alcohol Intake from Mouthwash
}

\author{
Tanja Wirth ${ }^{1,2}$, Michal M. Kawecki ${ }^{1}$, Janice Reeve ${ }^{3}$, Claudia Cunningham ${ }^{4}$, Iain Bovaird ${ }^{4}$, \\ Tatiana V. Macfarlane ${ }^{1}$
}

${ }^{1}$ School of Medicine and Dentistry, University of Aberdeen, Aberdeen, United Kingdom.

${ }^{2}$ University of Bremen, Bremen, Germany.

${ }^{3}$ Department of Clinical Biochemistry, Aberdeen Royal Infirmary, Aberdeen, United Kingdom.

${ }^{4}$ NHS Grampian, Aberdeen, United Kingdom.

Corresponding Author:

Tatiana V. Macfarlane

School of Medicine and Dentistry

University of Aberdeen Dental School

Cornhill Road, Foresterhill

Aberdeen, AB25 2ZR

United Kingdom

Phone: (+44) (0)1224 551585

Fax: (+44) (0)1224 554761

E-mail: tatiana.macfarlane@abdn.ac.uk

\begin{abstract}
Objectives: The purpose of this study was to develop and validate the mouthwash use questionnaire to determine the lifetime exposure to alcohol from mouthwash and verify that it was suitable for use in general population.

Material and Methods: Data were available from three consecutive studies, all collecting information on mouthwash use. In addition, supermarkets and online stores were screened for the brands of mouthwash they sold. Alcohol content of mouthwash was identified from various sources, including laboratory measurements. Alcohol-containing mouthwash use was converted to glasses of wine equivalent.

Results: Mouthwash was used by $62 \%$ of the participants, and the main benefits reported were refreshment of bad breath (75\%), elimination of bacteria (68\%) and reduction of plaque formation (47\%). Majority mouthwashes used by the participants contained alcohol (61\%). Life-time exposure from alcohol in mouthwash was relatively small for most of the study participants: $79 \%$ had rinsed for less than one year with alcohol equivalent of one glass of wine per day. There was substantial agreement in mouthwash reporting between different occasions (Kappa >0.62).

Conclusions: The questionnaire can be used to investigate mouthwash use in the general population and to measure alcohol intake from mouthwash.
\end{abstract}

Keywords: mouthwashes; oral health; oral cancer; alcohols; epidemiology; questionnaires.

Accepted for publication: 28 September 2012.

To cite this article:

Wirth T, Kawecki MM, Reeve J, Cunningham C, Bovaird I, Macfarlane TV. Can Alcohol Intake from Mouthwash be Measured in Epidemiological Studies? Development and Validation of Mouthwash Use Questionnaire with Particular Attention to Measuring Alcohol Intake from Mouthwash.

J Oral Maxillofac Res 2012;3(3):e1

URL: http://www.ejomr.org/JOMR/archives/2012/3/e1/v3n3e1ht.pdf

doi: $10.5037 /$ jomr.2012.3301 


\section{INTRODUCTION}

Mouthwashes are fluids containing active components with antiseptic, antibiotic, antifungal, astringent and anti-inflammatory effects on the oral cavity and pharynx [1]. In general population, mouth rinses are commonly used to maintain fresh breath. They are also recommended to prevent oral diseases, such as caries and gingivitis, and to reduce plaque formation [2].

Various types of mouthwash are available on the market. They differ in content and as such are tailored to specific requirements. Some of the key ingredients include chlorhexidine gluconate, benzydamine hydrochloride, cetylpyridinium chloride, sodium benzoate, triclosan, hydrogen peroxide, povidone-iodine, fluoride, sodium bicarbonate, essential oils and ethanol [ $\underline{3}]$.

Mouthwashes containing chlorhexidine gluconate currently have the status of a gold standard for the inhibition of plaque formation and reduction of gingivitis $[\underline{2}, \underline{3}]$. However, these mouthwashes are not recommended for use over a prolonged period of time as they have associated side effects, such as tooth staining, taste alteration and burning sensation [2]. Benzydamine hydrochloride acts as an analgesic, anti-inflammatory, antimicrobial and anaesthetic and is often used in mouthwash to supplement chlorhexidine gluconate. Cetylpyridinium chloride, sodium benzoate and triclosan are added to prevent plague and gingivitis, although these effects have also been questioned $[\underline{4}, \underline{5}]$. It is recommended to rinse with mouthwash containing hydrogen peroxide when suffering from acute ulcerative disease, gingivitis or to enhance oral hygiene and diminish dental staining. Fluoride prevents and reduces dental caries while sodium bicarbonate protects against xerostomia and erosion [5] . Essential oils, used in mouthwash, permeate the plaque biofilm to eliminate bacteria and microorganisms and can reduce plague, gingivitis and halitosis [3].

In several commercial mouthwashes ethanol is added as a solvent for some of the active properties mentioned above. At a high concentration ethanol also plays an important role as a preservative and antiseptic agent [6]. However, alcohol-containing mouthwashes can be quite aggressive fluids. It is possible that they damage the tissue of the oral cavity and cause epithelium detachment, mucosal ulcerations, gingivitis, petechias and white lesions in long term users [1].

Role of mouthwash in the development of oral cancer remains controversial. Several studies showed conflicting results with some reporting an increased risk of developing oral, pharyngeal and laryngeal cancers with regular mouthwash use [7-9] while others showed no statistically significant association [10-13].
In 2009, Lachenmeier et al. were the first to examine salivary acetaldehyde production after use of alcoholcontaining mouthwashes [14]. Acetaldehyde is a product of alcohol metabolism and already known to be a carcinogen in animals, such as rats and hamsters [15]. Results showed that mouthwashes studied led to salivary acetaldehyde concentrations similar to those found after alcohol consumption. It was therefore concluded that carcinogenic effects of alcohol-containing mouthwashes could not be excluded [14].

Previous studies revealed that mouthwashes are used by the general population $[16,17]$. In a multicentre case-control study conducted in ten European countries $42 \%$ of all participants rinsed with mouthwash [16]. Mouthwash use is associated with socio-demographic, health and behavioural factors [17]. Alcoholic beverages were extensively studied by type [19], with varying alcohol content in liquor, wine and beer. Therefore, to examine the effects of mouth rinses, it is essential to know the extent of alcohol exposure. Previous studies investigating role of mouthwash in oral cancer $[\underline{8}, 9]$ inquired whether mouthwash contained alcohol. However, the amount is not always available from labels on alcohol-containing mouthwashes. There is also a wide variation in alcohol content of mouthwashes [ $\underline{3}]$.

We attempted to develop a questionnaire to determine the lifetime exposure to alcohol from mouthwash and validate it in general population.

\section{MATERIAL AND METHODS Data collection}

Ethical approval for the study was given by The College of Life Sciences and Medicine Ethics Review Board, University of Aberdeen.

Data were available from three consecutive studies: in each study questionnaires were sent to participants of the preceding study (Figure 1).

Pilot phase of the Grampian Adult Dental Health Survey [17] was carried out in July and August 2009 on randomly selected residents in the Grampian region of Scotland (Group 1). The questionnaire included questions on general health, disability, dental care and oral health (including mouthwash use).

Between July and November 2011 the full version of the Mouthwash Use Questionnaire (MUQ) was sent to the participants of the pilot phase who had agreed to be contacted again for further studies and had provided their contact details (Group 2).

MUQ consisted of twelve questions regarding mouthwash use, frequency of use, number of mouthfuls, 


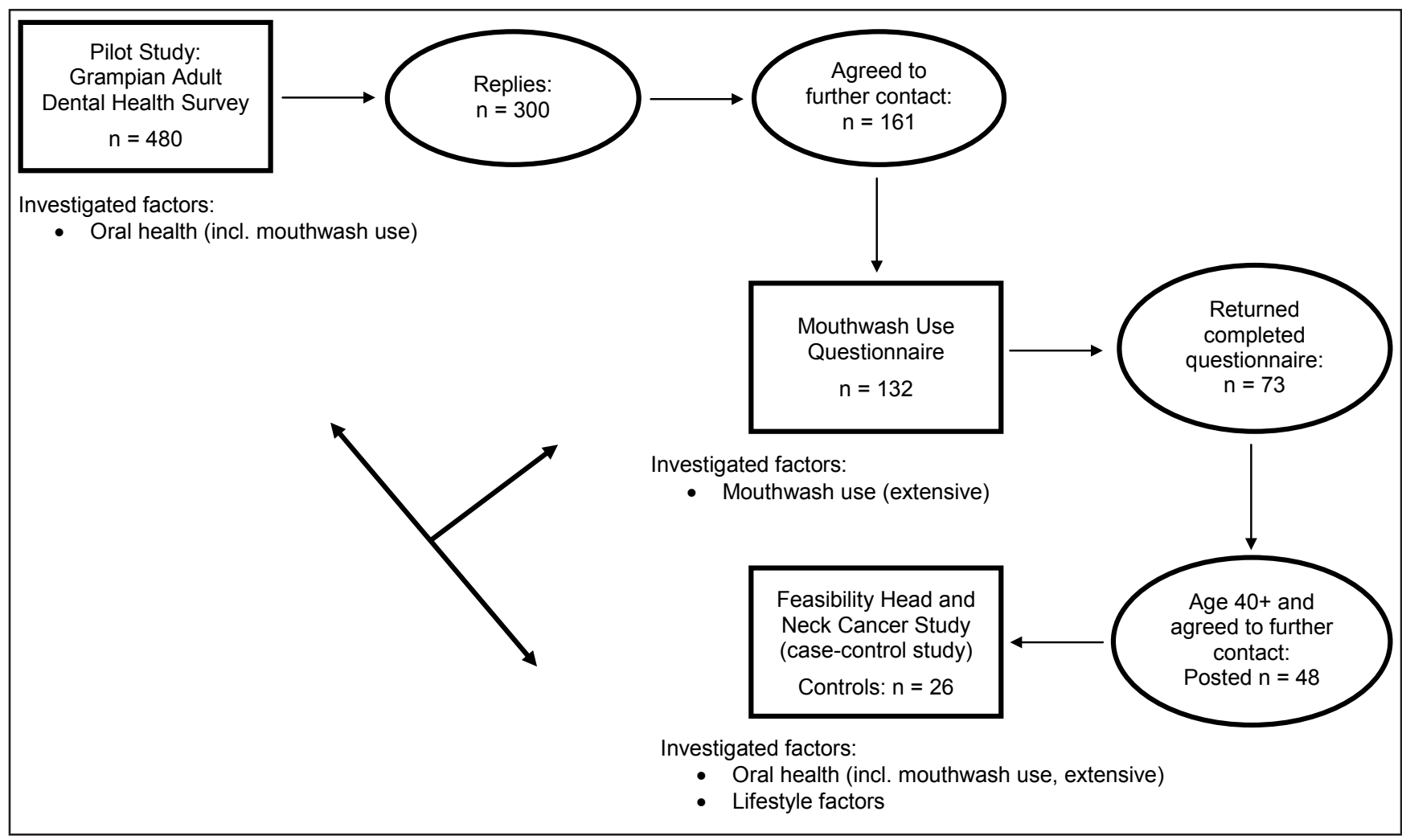

Figure 1. Available data.

dilution of mouthwash and the time the mouthwash is kept inside the mouth. Furthermore, participants were asked about their reasons for rinsing with mouthwash and the benefits they perceived from mouthwash use. In developing the questionnaire, particular interest was taken in collecting information on the alcohol content of different mouthwashes. Therefore, a question was included asking about the specific brand of mouthwash currently used by participants. A list with descriptions and coloured images of all mouthwashes available on the United Kingdom at that time market was provided as part of the questionnaire.

Participants who had filled in the MUQ and who had agreed to be contacted again for further research projects were used as controls in the Feasibility Study of Cancer of the Head and Neck, Genetics and Environment in Grampian (Group 3). For this case-control study a group of incident cases with cancer of the oral cavity, oropharynx and larynx identified from Aberdeen Royal Infirmary and a comparable group of controls were recruited between August and November 2011. All participants either filled in a lifestyle questionnaire at home, and returned it by post, or attended an interview with a trained research nurse where they completed the lifestyle questionnaire which included MUQ.

Alongside with these studies, large supermarkets and department stores in Aberdeen, Scotland, as well as several online stores were screened to determine which brands of mouthwash they sold.

\section{Determination of alcohol content in mouthwash}

The alcohol by volume (ABV) of each mouthwash was identified from labels, internet sources, previous studies $[1,6]$, via email contact with the manufacturer or through direct measurement in the laboratory. For one mouthwash the ABV was not provided, and as it was no longer commercially available it could not be determined by the laboratory. For this mouthwash the $A B V$ was assumed based on a very similar mouthwash of another brand, to avoid missing data.

Ethanol content of 25 of the mouthwashes, for which there were no data on alcohol content, was examined in the laboratory using a headspace gas chromatographyflame ionisation detection (GC-FID) method. Chromatographic separation was performed on a dual column system $\left(\mathrm{Rtx}^{\circledR}-\mathrm{BAC} 1\right.$ and $\mathrm{Rtx}^{\circledR}-\mathrm{BAC} 2$ columns; Restek, UK) at $40{ }^{\circ} \mathrm{C}$ with FID detection at $250{ }^{\circ} \mathrm{C}$. An ethanol calibration curve was prepared ranging from $5-400 \mathrm{mg} / \mathrm{dL}$ using ethanol standard solutions at 400 and $200 \mathrm{mg} / \mathrm{dL}$ (Medichem Diagnostic, Germany). Linearity was observed with ethanol concentrations up to $400 \mathrm{mg} / \mathrm{dL}(\mathrm{y}=0.002 \mathrm{x}+0.0034 ; \mathrm{r}=0.999)$.

The analytical and functional sensitivity of the assay were previously defined in-house as $1 \mathrm{mg} / \mathrm{dL}$ and $5 \mathrm{mg} / \mathrm{dL}$, respectively. Internal ethanol quality control materials (Bio-Rad Laboratories, UK) levels 1 (49.3 $61.3 \mathrm{mg} / \mathrm{dL}), 2(141.6-161.6 \mathrm{mg} / \mathrm{dL})$ were assessed at the beginning, middle and end of the assay run. 
Mouthwash was mixed with $2.4 \mathrm{M} \mathrm{NaCl}$ (1: 9 dilution) containing n-propyl alcohol $(5 \% \mathrm{v} / \mathrm{v})$ as internal standard. Ethanol levels exceeding the linearity of the assay were diluted $1: 100$ in $2.4 \mathrm{M} \mathrm{NaCl}$. The ethanol content of mouthwash was expressed as percent weight per volume $(\% \mathrm{w} / \mathrm{v})$.

\section{Statistical analysis}

All statistical analysis was carried out using IBM ${ }^{\circledR}$ SPSS Statistics for Windows version 19. Completed data from the three studies were merged and reported using descriptive statistics. Kappa values and corresponding 95\% confidence intervals (CI) were determined using an online calculator available from: http://faculty. vassar.edu/lowry/kappa.html in addition to SPSS. Kappa statistic was interpreted according to ranges for strength of agreement developed by Landis and Koch [20]: $<0.00$ poor, $0.00-0.20$ slight, $0.21-0.40$ fair, $0.41-0.60$ moderate, $0.61-0.80$ substantial, $0.81-1.00$ almost perfect.

Years of mouthwash use were calculated by using the age of participants when they filled in the questionnaire and their reported age when they started rinsing with their current mouthwash.

Glass of wine was used as a unit of analysis. One mouthful was considered equivalent to $20 \mathrm{~mL}$, which was in keeping with instructions for use provided by the most popular mouthwash brands. The number of alcohol units of mouthwash was determined by multiplying its ABV by $20 \mathrm{~mL}$ and dividing by 1000 $\mathrm{mL}$. Numbers generated were then multiplied by the number of mouthfuls participants used. One alcohol unit was considered to equal half a standard glass $(175 \mathrm{~mL})$ of wine (ABV 12\%) as suggested by drinkaware.co.uk and Gill et al. [18]. Therefore results were multiplied by 0.5 to obtain the number of glasses of wine rinsed per use of mouthwash. These results were multiplied by the frequency of use. Factors used were 0.5 ( $<$ once a week), 1.5 (once or twice a week), 3 (every other day), 7 (once a day), 14 (twice a day) and 21 (three times a day) to estimate number of glasses of wine rinsed per week. Additionally, years rinsed with one glass of wine equivalent per day were calculated similar to packyears of smoking. Number of glasses of wine equivalent rinsed per day were multiplied by years of usage.

Content validity was measured by investigating whether the most frequently used mouthwash brands by the study population were also the brands most often available in supermarkets and online stores. In addition, frequency of tooth brushing and flossing was compared to frequency of mouthwash use using Spearman correlation coefficient. MUQ was assessed for reliability by comparing information on mouthwash use from Group 2 to the data collected from Groups 1 and 3 using Kappa statistics.

\section{RESULTS}

The participation rate in the pilot phase of the Grampian Adult Dental Health Survey was 63\% (300 individuals out of 480) (Group 1). Over half of the participants were female $(\mathrm{n}=158,53 \%)$. The mean age (standard deviation; SD) of the study population was $55.8(16.8)$ years and ranged from 25 to 96 years.

132 of the original participants included in the pilot phase of the Grampian Adult Dental Health Survey received the full mouthwash use questionnaire. Of these, $73(55 \%)$ participants returned completed questionnaires. Forty-five (62\%) participants were female. The mean age was 54.1 (14.6) years and ranged from 27 to 80 years.

From Group 2 forty-eight participants were asked to serve as controls in the Feasibility Head and Neck Cancer Study. A completed lifestyle questionnaire was obtained from 26 participants (Group 3), leading to a participation rate of $54 \%$. Fifteen (58\%) participants were male and the mean age was 63.0 (10.2) years (Range 46 - 81 years).

In Group 2 twelve participants (16\%) had never used mouthwash (Table 1). 16 participants $(22 \%)$ had rinsed with mouthwash in the past while a majority of $45(62 \%)$ were currently using mouthwash. Most of the current users had started to rinse with mouthwash within the last five years (59\%), $24 \%$ had been using mouthwash for 6 to 15 years and $9 \%$ for 16 to 25 years. Three individuals had been using mouthwash for more than 25 years. For eleven of the participants the number of years using mouthwash could not be reported, due to missing data on the questionnaire.

The majority of participants rinsed with mouthwash either once $(27 \%)$ or twice daily $(24 \%)$. Nine percent rinsed every other day whilst $16 \%$ used mouthwash once or twice weekly. $24 \%$ of participants rinsed with mouthwash less than once weekly. Usually mouthwash was used within five minutes of brushing teeth. The majority of participants $(89 \%)$ rinsed with one mouthful of mouthwash, $93 \%$ did not dilute the mouthwash and $56 \%$ of participants rinsed for more than 20 seconds. No one swallowed the mouthwash after use.

Twenty-one (51\%) participants surveyed used mouthwash containing no ethanol. All other participants appeared to rinse with an alcohol-containing mouthwash (61\%). These numbers do not add up to $100 \%$, because five participants used two different mouthwash brands and were counted twice, while four participants did not report which brand they used. 
Table 1. Mouthwash use

\begin{tabular}{|c|c|c|}
\hline Characteristics & $\begin{array}{c}\text { Group 2a } \\
\text { N (\%) }\end{array}$ & $\begin{array}{c}\text { Group 3 }^{\mathbf{b}} \\
\text { N (\%) } \\
\end{array}$ \\
\hline \multicolumn{3}{|l|}{ Ever used mouthwash } \\
\hline No & $12(16.44)$ & $10(38.46)$ \\
\hline Yes & $61(83.56)$ & $16(61.54)$ \\
\hline \multicolumn{3}{|l|}{ Current use of mouthwash } \\
\hline Never used & $12(16.44)$ & $10(38.46)$ \\
\hline Used in the past & $16(21.92)$ & $5(19.23)$ \\
\hline Current use/1 year ago & $45(61.64)^{\mathrm{c}}$ & $11(42.31)^{\mathrm{d}}$ \\
\hline \multicolumn{3}{|l|}{ Years of using mouthwash } \\
\hline$\leq 5$ years & $20(58.82)$ & $1(14.29)$ \\
\hline $6-15$ years & $8(23.53)$ & $3(42.86)$ \\
\hline $16-25$ years & $3(8.82)$ & $2(28.57)$ \\
\hline$>25$ years & $3(8.82)$ & $1(14.29)$ \\
\hline Missing & 11 & 4 \\
\hline \multicolumn{3}{|l|}{ Frequency of use } \\
\hline$<$ Once/week & $11(24.44)$ & $3(27.27)$ \\
\hline Once or twice/week & $7(15.56)$ & $2(18.18)$ \\
\hline Every other day & $4(8.89)$ & $1(9.09)$ \\
\hline Once/day & $12(26.67)$ & $2(18.18)$ \\
\hline Twice/day & $11(24.44)$ & $2(18.18)$ \\
\hline Three times/day & - & $1(9.09)$ \\
\hline \multicolumn{3}{|l|}{ Time interval between brushing teeth and use of mouthwash } \\
\hline$<1 \mathrm{~min}$ & $29(64.44)$ & $6(54.55)$ \\
\hline About 5 min & $11(24.44)$ & $3(27.27)$ \\
\hline About 1 hour & $2(4.44)$ & - \\
\hline About 2 hours & $1(2.22)$ & - \\
\hline Other & $2(4.44)$ & $2(18.18)$ \\
\hline \multicolumn{3}{|l|}{ Dilute mouthwash } \\
\hline No & $42(93.33)$ & $9(81.82)$ \\
\hline Yes & $3(6.67)$ & $2(18.18)$ \\
\hline \multicolumn{3}{|l|}{ Amount of mouthfuls } \\
\hline Only one & $40(88.89)$ & $11(100)$ \\
\hline Two or more & $5(11.11)$ & - \\
\hline \multicolumn{3}{|l|}{ Time kept in mouth } \\
\hline A few seconds $(\leq 20 \mathrm{sec}$. $)$ & $19(44.19)$ & $6(54.55)$ \\
\hline Longer $(>20 \mathrm{sec})$. & $24(55.81)$ & $5(45.45)$ \\
\hline Missing & 2 & - \\
\hline \multicolumn{3}{|l|}{ Swallow mouthwash } \\
\hline No & $45(100)$ & $11(100)$ \\
\hline Yes & - & - \\
\hline \multicolumn{3}{|l|}{ Mouthwash contains alcohol ${ }^{\mathrm{e}}$} \\
\hline No & $21(51.22)$ & $3(27.27)$ \\
\hline Yes & $25(60.98)$ & $8(72.73)$ \\
\hline Missing & 4 & - \\
\hline \multicolumn{3}{|c|}{ Glasses of wine equivalent rinsed per year (users of alcohol containing mouthwash) } \\
\hline $1-25$ & $13(52)$ & $5(62.5)$ \\
\hline $26-50$ & $5(20)$ & - \\
\hline $51-100$ & $3(12)$ & $2(25)$ \\
\hline $101-150$ & - & - \\
\hline $151-200$ & $3(12)$ & - \\
\hline$>200$ & $1(4)$ & $1(12.5)$ \\
\hline \multicolumn{3}{|c|}{ Years rinsed with one glass of wine equivalent per day (users of alcohol containing mouthwash) } \\
\hline $0.0-0.4$ & $13(68.42)$ & $2(40)$ \\
\hline $0.5-0.9$ & $2(10.53)$ & - \\
\hline $1-1.9$ & $2(10.53)$ & $2(40)$ \\
\hline $2-2.9$ & - & $1(20)$ \\
\hline$>3$ & $2(10.53)$ & - \\
\hline Missing & 6 & 3 \\
\hline
\end{tabular}

${ }^{a}$ Group 2 are participants who filled in the mouthwash use questionnaire.

${ }^{\mathrm{b}}$ Group 3 are controls of the Feasibility Head and Neck Cancer Study.

'Questionnaire asked for the current use of mouthwash.

${ }^{\mathrm{d}}$ Group 3 was asked about mouthwash use one year ago.

eNumbers do not add up to total, because 5 participants in the Mouthwash Use project used two different mouthwash brands. 
The conversion of the amount of alcohol containing mouthwash rinsed by participants into glasses of wine resulted in $52 \%$ rinsing with the equivalent of 1 to 25 wine glasses per year. Four individuals rinsed with equivalent of more than 150 glasses of wine per year. Numbers of years rinsed with one glass of wine equivalent per day remained relatively small for most study participants. A majority of $68 \%$ had rinsed less than half a year with one glass of wine per day. A further $11 \%$ remained under one year (Table 1 ).

When asked about the reasons for using mouthwash, $32(71 \%)$ participants elected to use it themselves. Ten participants stated that it was recommended by their dentist, in three of these ten cases because of gum disease. The perceived benefit of mouthwash use for most of the study population was refreshment of bad breath $(75 \%)$. This was followed closely by elimination of bacteria, reduction of plaque formation and the ability to reach difficult places in the mouth (Table 2).

The most common brand of mouthwash used in Group 2 was Listerine (Johnson \& Johnson Limited, Maidenhead, UK) (30\%) (Table 3). This was followed by Colgate (Colgate Palmolive, Guilford, UK) (15\%), Corsodyl (Corsodyl, Brentford, UK) (13\%), Aquafresh (GlaxoSmithKline, Uxbridge, UK) (11\%) and Dentyl ph (Boots contract manufacturing, Nottingham, UK) $(11 \%)$. Other brands were not as frequently used among the study population. Investigation of nine large supermarkets and department stores in Aberdeen and eight online stores showed that Listerine, the mouthwash brand most often used by our study population, was available in all of them. The brands Aquafresh, Colgate, Corsodyl and Dental ph, which were also more commonly used by participants,
Table 2. Reasons and benefits of mouthwash use as suggested by study participants

\begin{tabular}{lc}
\hline \multicolumn{1}{c}{ Characteristics } & $\begin{array}{c}\text { Group } \mathbf{2}^{\mathbf{a}} \\
\mathbf{N}(\mathbf{\%})\end{array}$ \\
\hline Reasons & \\
Chosen by myself & $32(71.11)$ \\
Recommended by a dentist & $10(22.22)$ \\
Recommended by a doctor & $1(2.22)$ \\
Receding gums and loose teeth & $1(2.22)$ \\
Daughter uses it & $1(2.22)$ \\
Recommended by a Chemist for sore throat + & $1(2.22)$ \\
found it very effective & \\
\hline Benefits & \\
Refreshment of bad breath & $55(75.34)$ \\
Elimination of bacteria & $50(68.49)$ \\
Reduction of plaque formation & $34(46.58)$ \\
Ability to reach difficult places in the mouth & $33(45.21)$ \\
Prevention of cavities & $24(32.88)$ \\
Prevention of periodontitis and gingivitis & $21(28.77)$ \\
Removal of tartar & $20(27.40)$ \\
Improvement of oral wound healing & $19(26.03)$ \\
Strengthening of tooth enamel & $16(21.92)$ \\
General health improvement & $14(19.18)$ \\
Reduction of dentine sensitivity & $13(17.81)$ \\
Alleviation of oral pathology & $13(17.81)$ \\
Relieve of pain & $10(13.70)$ \\
Stain removal & $9(12.33)$ \\
As a follow-up to oral surgery & $8(10.96)$ \\
Relieve of dry mouth & $7(9.59)$ \\
Reduction of frequency of tooth brushing & $4(5.48)$ \\
As a gargle & $1(1.37)$ \\
Preart protection & $1(1.37)$ \\
Refreshtion of colds & $1(1.37)$ \\
& $1(1.37)$ \\
\hline
\end{tabular}

${ }^{a}$ Group 2 are participants who filled in the mouthwash use questionnaire.

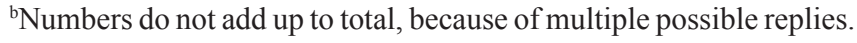

Table 3. Mouthwash brands used by study participants according to shops where they are available

\begin{tabular}{lcccc}
\hline \multirow{2}{*}{$\begin{array}{c}\text { Mouthwash } \\
\text { brand }\end{array}$} & $\begin{array}{c}\text { Used by Group 2a } \\
(\mathrm{n}=45)\end{array}$ & $\begin{array}{c}\text { Online stores } \\
(\mathrm{n}=8)\end{array}$ & $\begin{array}{c}\text { Large supermarkets and department stores } \\
(\mathrm{n}=9)\end{array}$ & $\begin{array}{c}\text { Total } \\
(\mathrm{n}=17)\end{array}$ \\
\cline { 2 - 5 } & $\mathbf{N}(\mathbf{\%})^{\mathbf{b}}$ & $\mathbf{N} \mathbf{( \% )}$ & $\mathbf{N ~ ( \% )}$ & $\mathbf{N}(\mathbf{\%})$ \\
\hline Listerine & $14(30.43)$ & $8(100)$ & $9(100)$ & $17(100)$ \\
Colgate & $7(15.22)$ & $7(87.5)$ & $7(77.78)$ & $14(82.35)$ \\
Corsodyl & $6(13.04)$ & $8(100)$ & $7(77.78)$ & $15(88.24)$ \\
Aquafresh & $5(10.87)$ & $6(75)$ & $8(88.89)$ & $14(82.35)$ \\
Dentyl pH & $5(10.87)$ & $8(100)$ & $6(66.67)$ & $14(82.35)$ \\
Retardex & $2(4.35)$ & $7(87.5)$ & $4(44.44)$ & $11(64.71)$ \\
ASDA & $1(2.17)$ & $1(12.5)$ & $1(11.11)$ & $2(11.76)$ \\
Boots & $1(2.17)$ & $1(12.5)$ & $1(11.11)$ & $2(11.76)$ \\
Gengigel & $1(2.17)$ & $2(25)$ & $2(22.22)$ & $4(23.53)$ \\
Optima & $1(2.17)$ & $1(12.5)$ & - & $1(5.88)$ \\
Oral-B & $1(2.17)$ & $6(75)$ & $6(66.67)$ & $12(70.59)$ \\
Oraldene & $1(2.17)$ & $5(62.5)$ & $6(66.67)$ & $11(64.71)$ \\
Sensodyne & $1(2.17)$ & $6(75)$ & $7(77.78)$ & $13(76.47)$ \\
\hline
\end{tabular}

${ }^{a}$ Group 2 are participants who filled in the mouthwash use questionnaire.

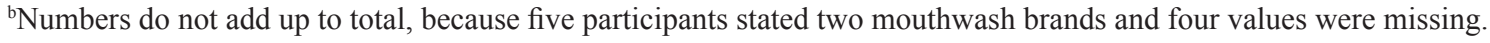


were also available in the majority of the stores examined. The less used brands, such as Optima (Optima Health UK Ltd, Bradford, UK and Gengigel (Molar Ltd, Somerset, UK), were sold in fewer shops. This was not the case for all of the less used brands. Oral-B (Procter \& Gamble UK, Weybridge, UK) and Sensodyne (GlaxoSmithKline, Uxbridge, UK) were often available, but their use was not frequent in Group 2 (Table 3). These results overall demonstrate that the content of the questionnaire was valid.

There was a significant relationship between frequency of mouthwash use and frequency of tooth brushing (Spearman correlation 0.14, $\mathrm{P}=0.026$ ) and flossing (Spearman correlation $0.16, \mathrm{P}=0.015$ ).

Majority of participants who reported that they currently used mouthwash in the Pilot phase of the Grampian Adult Dental Health Survey also reported this in the mouthwash use questionnaire $(85.7 \%)$. For frequency of use, substantial agreement was found comparing Group 1 and 2 (weighted Kappa $=0.62[0.43,0.77]$ ).

Of the 21 individuals, who reported they had ever used mouthwash in the MUQ study, 15 (71.4\%) also reported this in the Feasibility Head and Neck Cancer Study. When comparing frequency of mouthwash use on two occasions (Group 2 and 3), reliability was found to be substantial $(\mathrm{Kappa}=0.77[0.38,0.97])$. For these groups the alcohol content of the mouthwash brands used was also investigated. Data were only available for eight participants who gave the information in both studies. The overall agreement was found to be perfect $(100 \%)$.

\section{DISCUSSION}

Mouthwash was commonly used among the study population and the majority of participants saw its benefit in the refreshing of bad breath. The most frequent mouthwash brands used by participants were widely available in a variety of supermarkets and online stores. More than half of the reported brands contained alcohol. There was substantial reliability in reporting frequency of use.

A limiting factor for the results of reliability of the questionnaire was the long time period between the Pilot Grampian Adult Dental Health Survey and the Mouthwash Use Project. During the two years between these studies, participants could certainly have changed their patterns of mouthwash use, leading to lower Kappa values. For use in the Feasibility Head and Neck Cancer Study, questions on mouthwash use had to be adapted to its specific study design. Therefore, all questions on mouthwash use asked for the patterns of use one year ago and not for the current state. This might also limit the results for reliability when comparing Groups 2 and 3.

The MUQ contained extensive questions on mouthwash use and, therefore, gives distinct information on the habits of participants, as well as their preferred brands. This makes it possible to collect information on the alcohol content of the mouthwashes. In this project, the alcohol content of mouthwash was expressed as glasses of wine. The numbers of glasses rinsed per year varied greatly among participants, but remained relatively small for the majority, as well as, years rinsed with one glass of wine equivalent per day.

Polesel et al. [21] suggested the use of regression spline models as a method to estimate dose-response relationships between ethanol consumption and risk of head and neck cancers. Their study identified that the risk of developing cancers of the oral cavity, pharynx, larynx or oesophagus increased with the consumption of 1.5 litres of wine per day. As can be seen from our results, the exposure of the oral cavity to ethanol from mouthwash use is much lower than that of alcohol consumption. Therefore, the examination of doseresponse is difficult.

Very few studies which assessed the use of mouthwash and the associated risk of cancer development have collected information on mouthwash brands used and alcohol content $[\underline{8}, \underline{12}, 22-24]$.

Within a case series Weaver et al. [22] identified eleven non-smoking, non-alcohol drinking patients with squamous cell carcinoma of the head and neck. Of these patients, ten had used mouthwash extensively with most brands used containing $25 \%$ alcohol. In contrast, Mashberg et al. [22] found no statistically significant association between the brand of mouthwash used and oral or pharyngeal cancer. Morse et al. [24] also observed no increased risk for oral epithelial dysplasia among participants who used mouthwash with high alcohol concentration. In 1991, in their study examining the risk of developing oral and pharyngeal cancer, Winn et al. [8] categorized mouthwash by alcohol content as none, low $(<25 \%)$ and high $(\geq 25 \%)$. Their results demonstrated an increased risk of developing oral and pharyngeal cancers with mouthwash containing $\geq 25 \%$ ethanol compared to those with none or low levels. From these findings it can be suggested that a differentiation between alcohol-containing and alcohol-free mouthwashes should be considered in future studies. Previous studies have highlighted a lack of information on brands of mouthwash used, alcohol content of the brands and duration of rinsing with the mouthwash as major limitations of their work [9].

The mouthwash use questionnaire, used in this study, combined all of these variables and, therefore, is an important tool for future studies examining the risks 
and benefits of mouthwash use. However, mouthwash brands did not always list the alcohol content on the labelling, making the exposure of the oral cavity to alcohol difficult to determine.

Further high-quality studies are required to differentiate the effects of alcohol-containing and alcohol-free mouthwash use on the development of on head and neck cancers. These studies should consider regression spline models as an option for examining dose-response relationships.

\section{CONCLUSIONS}

The mouthwash use questionnaire was proven to be a valid and reliable tool for the examination of mouthwash use in the general population. Future studies should support more accurate assessment of alcohol content in mouthwash which would allow oral cavity exposure to be determined as well as its associated risk for oral cancer development.

\section{ACKNOWLEDGEMENTS AND DISCLOSURE STATEMENTS}

This project was partly supported by the NHS Grampian Endowment fund. We are very grateful to all participants for completing the questionnaires. Tanja Wirth worked on this project while taking part in an Erasmus student placement under the European Lifelong Learning Programme. Michal M. Kawecki was supported by HotStart scholarship. The authors report no conflict of interest related to this study.

\section{REFERENCES}

1. Carretero Peláez MA, Esparza Gómez GC, Figuero Ruiz E, Cerero Lapiedra R. Alcohol-containing mouthwashes and oral cancer. Critical analysis of literature. Med Oral. 2004 Mar-Apr;9(2):120-3, 116-20. Review. English, Spanish. [Medline: 14990877] [FREE Full Text]

2. Moran JM. Home-use oral hygiene products: mouthrinses. Periodontol 2000. 2008;48:42-53. Review. [Medline: 18715355] [doi: 10.1111/j.1600-0757.2008.00260.x]

3. Farah CS, McIntosh S, McCullough MJ. Mouthwashes. Aust Prescr. 2009 Dec;32(6):162-4.

URL: http://www.australianprescriber.com/magazine/32/6/162/4/

4. Nelson RF, Rodasti PC, Tichnor A, Lio YL. Comparative study of four over-the-counter mouthrinses claiming antiplaque and/or antigingivitis benefits. Clin Prev Dent. 1991 Nov-Dec;13(6):30-3 [Medline: 1813203]

5. Mo Moran J, Addy M. The effects of a cetylpyridinium chloride prebrushing rinse as an adjunct to oral hygiene and gingival health. J Periodontol. 1991 Sep;62(9):562-4. [Medline: 1941495] [doi: 10.1902/jop.1991.62.9.562]

6. McCullough MJ, Farah CS. The role of alcohol in oral carcinogenesis with particular reference to alcohol-containing mouthwashes. Aust Dent J. 2008 Dec;53(4):302-5. Review [Medline: 19133944] [doi: 10.1111/j.1834-7819.2008.00070.x]

7. Blot WJ, Winn DM, Fraumeni JF Jr. Oral cancer and mouthwash. J Natl Cancer Inst. 1983 Feb;70(2):251-3. [Medline: 6571933]

8. Winn DM, Blot WJ, McLaughlin JK, Austin DF, Greenberg RS, Preston-Martin S,Schoenberg JB, Fraumeni JF Jr. Mouthwash use and oral conditions in the risk of oral and pharyngeal cancer. Cancer Res. 1991 Jun 1;51(11):3044-7. [Medline 2032242] [ [FREE Full Text]

9. Guha N, Boffetta P, Wünsch Filho V, Eluf Neto J, Shangina O, Zaridze D, Curado MP, Koifman S, Matos E, Menezes A, Szeszenia-Dabrowska N, Fernandez L, Mates D, Daudt AW, Lissowska J, Dikshit R, Brennan P. Oral health and risk of squamous cell carcinoma of the head and neck and esophagus: results of two multicentric case-control studies. Am J Epidemiol. 2007 Nov 15;166(10):1159-73. Epub 2007 Aug 30. [Medline: 17761691] [doi: 10.1093/aje/kwm193] [FREE Full Text]

10. Divaris K, Olshan AF, Smith J, Bell ME, Weissler MC, Funkhouser WK, Bradshaw PT. Oral health and risk for head and neck squamous cell carcinoma: the Carolina Head and Neck Cancer Study. Cancer Causes Control. 2010 Apr;21(4):56775. Epub 2010 Jan 5. [Medline: 20049634] [doi: 10.1007/s10552-009-9486-9] [FREE Full Text]

11. Kabat GC, Hebert JR, Wynder EL. Risk factors for oral cancer in women. Cancer Res. 1989 May 15;49(10):2803-6 [Medline: 2713863] [FREE Full Text]

12. Winn DM, Diehl SR, Brown LM, Harty LC, Bravo-Otero E, Fraumeni JF Jr, Kleinman DV, Hayes RB. Mouthwash in the etiology of oral cancer in Puerto Rico. Cancer Causes Control. 2001 Jun;12(5):419-29. [Medline: 11545457] [doi: 10.1023/A:1011291807468]

13. Young TB, Ford CN, Brandenburg JH. An epidemiologic study of oral cancer in a statewide network. Am J Otolaryngol. 1986 May-Jun;7(3):200-8. [Medline: 3728828] [doi: 10.1016/S0196-0709(86)80007-2] 
14. Lachenmeier DW, Gumbel-Mako S, Sohnius EM, Keck-Wilhelm A, Kratz E, Mildau G. Salivary acetaldehyde increase due to alcohol-containing mouthwash use: a risk factor for oral cancer. Int J Cancer. 2009 Aug 1;125(3):730-5. [Medline: 19444911] [doi: 10.1002/ijc.24381]

15. Re-evaluation of some organic chemicals, hydrazine and hydrogen peroxide. Proceedings of the IARC Working Group on the Evaluation of Carcinogenic Risks to Humans. Lyon, France, 17-24 February 1998. IARC Monogr Eval Carcinog Risks Hum. 1999;71 Pt 1:1-315. [Medline: 10507919]

16. Macfarlane TV, Macfarlane GJ, Oliver RJ, Benhamou S, Bouchardy C, Ahrens W, Pohlabeln H, Lagiou P, Lagiou A, Castellsague X, Agudo A, Merletti F, Richiardi L, Kjaerheim K, Slamova A, Schejbalova M, Canova C, Simonato L, Talamini R, Barzan L, Conway DI, McKinney PA, Znaor A, Lowry RJ, Thomson P, Healy CM, McCartan BE, Marron M, Hashibe M, Brennan P. The aetiology of upper aerodigestive tract cancers among young adults in Europe: the ARCAGE study. Cancer Causes Control. 2010 Dec;21(12):2213-21. Epub 2010 Sep 11. [Medline: 20835759] [doi: 10.1007/s10552-010-9641-3]

17. Macfarlane TV, Kawecki MM, Cunningham C, Bovaird I, Morgan R, Rhodes K, Watkins R. Mouthwash Use in general Population: Results from Adult Dental Health Survey in Grampian, Scotland. J Oral Maxillofac Res 2010(Oct-Dec); 1(4):e2. URL: http://www.ejomr.org/JOMR/archives/2010/4/e2/v1n4e2ht.htm [doi: 10.5037/jomr.2010.1402]

18. Gill JS, Donaghy M. Variation in the alcohol content of a 'drink' of wine and spirit poured by a sample of the Scottish population. Health Educ Res. 2004 Oct;19(5):485-91. [Medline: 15345708] [doi: 10.1093/her/cyg059]

19. Marron M, Boffetta P, Møller H, Ahrens W, Pohlabeln H, Benhamou S, Bouchardy C, Lagiou P, Lagiou A, Slámová A, Schejbalová M, Merletti F, Richiardi L, Kjaerheim K, Agudo A, Castellsague X, Macfarlane TV, Macfarlane GJ, Talamini R, Barzan L, Canova C, Simonato L, Biggs AM, Thomson P, Conway DI, McKinney PA, Znaor A, Healy CM, McCartan BE, Brennan P, Hashibe M. Risk of upper aerodigestive tract cancer and type of alcoholic beverage: a European multicenter case-control study. Eur J Epidemiol. 2012 Jul;27(7):499-517. Epub 2012 Jun 13. [Medline: 22692594] [doi: 10.1007/s10654-012-9699-1]

20. Landis JR, Koch GG. The measurement of observer agreement for categorical data. Biometrics. 1977 Mar;33(1):159-74. [Medline: 843571] [doi: 10.2307/2529310]

21. Polesel J, Dal Maso L, Bagnardi V, Zucchetto A, Zambon A, Levi F, La Vecchia C, Franceschi S. Estimating dose-response relationship between ethanol and risk of cancer using regression spline models. Int J Cancer. 2005 May 1;114(5):836-41. [Medline: 15609308] [doi: 10.1002/ijc.20756]

22. Mashberg A, Barsa P, Grossman ML. A study of the relationship between mouthwash use and oral and pharyngeal cancer. J Am Dent Assoc. 1985 May;110(5):731-4. [Medline: 3859544]

23. Weaver A, Fleming SM, Smith DB. Mouthwash and oral cancer: carcinogen or coincidence? J Oral Surg. 1979 Apr;37(4):250-3. [Medline: 285229]

24. Morse DE, Katz RV, Pendrys DG, Holford TR, Krutchkoff DJ, Eisenberg E, Kosis DL, Kerpel S, Freedman P, Mayne ST. Mouthwash use and dentures in relation to oral epithelial dysplasia. Oral Oncol. 1997 Sep;33(5):338-43. [Medline: 9415333] [doi: 10.1016/S1368-8375(97)00019-5]

\section{To cite this article:}

Wirth T, Kawecki MM, Reeve J, Cunningham C, Bovaird I, Macfarlane TV. Can Alcohol Intake from Mouthwash be Measured in Epidemiological Studies? Development and Validation of Mouthwash Use Questionnaire with Particular Attention to Measuring Alcohol Intake from Mouthwash.

J Oral Maxillofac Res 2012;3(3):e1

URL: http://www.ejomr.org/JOMR/archives/2012/3/e1/v3n3e1ht.pdf

doi: $10.5037 /$ jomr.2012.3301

Copyright (C) Wirth T, Kawecki MM, Reeve J, Cunningham C, Bovaird I, Macfarlane TV. Accepted for publication in the JOURNAL OF ORAL \& MAXILLOFACIAL RESEARCH (http://www.ejomr.org), 28 September 2012.

This is an open-access article, first published in the JOURNAL OF ORAL \& MAXILLOFACIAL RESEARCH, distributed under the terms of the Creative Commons Attribution-Noncommercial-No Derivative Works 3.0 Unported License, which permits unrestricted non-commercial use, distribution, and reproduction in any medium, provided the original work and is properly cited. The copyright, license information and link to the original publication on (http://www.ejomr.org) must be included. 